\title{
Medical practitioners as collectors and communicators of natural history in Ireland, 1680-1750
}

\author{
Alice Marples
}

In May 1688, the landowner and keen horticulturalist Sir Arthur Rawdon wrote from Moira to his fellow Co. Down-born friend, the young physician and naturalist, Hans Sloane:

Yours from Jamaica with an account of your Voyage I had, \& was overjoyed to hear you got so well there, \& that you agree so well with the country, I am sure ours here is a miserable one not a penny of mony to be got for anything in the world, no mannor of Trade the Tennants not able to pay their rents, nor the Landlords to forbear their tenants, so that most of the discourse is of Tenants dayly running away, \& tradesmen breaking, so that I believe no country was ever so poor, nor is there any prospect of amendment. ${ }^{1}$

In a later letter of June 1691, Rawdon apologised for his inability to join in with the reciprocal exchange of useful scholarly news with Sloane. He blamed this, in part, on the disruption caused by the Williamite-Jacobite War: 'I am sorry our countrey does not afford news of the same kind to retaliate you with, but now nothing can be done here for the noyse of war, which does not indeed trouble these parts only that the people run up so fast to the camp that we can not get workemen for any price. ${ }^{2}$ The following month, Victor Ferguson, a physician of Belfast, also referred to 'the confusion of these late times' in a letter to Sloane, but cited deeper issues with Ireland's intellectual culture as the main problem: 'It is indeed my great trouble and concern ... when I want converse or improvement; all must be hammered out of books and unpleasant meditation or study: none worth a farthing here to converse with or improve by, but reasoning from wrong sentiments and principals. ${ }^{3}$ 
In their letters to Sloane, Rawdon and Ferguson painted a bleak picture of the general state of learning in Ireland at the end of the seventeenth century. They felt far removed from the wider European Republic of Letters, unable to contribute news of equally learned activities and therefore unable to take part in this transcontinental community. ${ }^{4}$ Isolated and in short supply of books, botanical specimens and scientific instruments, they were forced to beg for them in achingly polite terms from the much more advantageously placed Sloane. Born in modest circumstances in Killyleagh in 1660, Sloane had left Ireland at a young age to seek out his medical education in London, Paris and Montpellier. ${ }^{5}$ He took his doctorate at the University of Orange in 1683 , and returned to London to set up an extremely profitable medical practice. As he did so, he became fully involved in the scholarly culture there: he was elected to the Royal Society in 1685 and the Royal College of Physicians in 1687. It was also in 1687 that he accompanied Christopher Monck, the second duke of Albermarle, to Jamaica as his personal physician. Sloane was the first trained naturalist to set foot on the island: he returned with 800 or so specimens (most of which had never before been seen in Europe), fortune, fame and an abundance of international contacts. With their help, Sloane would over his long lifetime ascend the ranks of society and build one of the biggest, broadest and most important collections in Early Modern Europe. Against reports of Sloane's exploits and international reputation, Rawdon and Ferguson might be forgiven for feeling they had to apologise for their inability to offer him any news of scholarly interest from Ireland.

Yet any assumption that Early Modern Ireland was a gloomy and poverty-stricken intellectual backwater has recently come under intense scrutiny. Concerted efforts have been made to establish the grounds for which there was a distinct Irish Enlightenment in the eighteenth century, and to reinstate the importance of the work of its seventeenthcentury thinkers, writers and actors, and discuss them within broader British, European and Atlantic trends. ${ }^{6}$ Ian McBride and others have, for example, established the critical importance of early Irish theological and philosophical discussion to British and American intellectual history. ${ }^{7}$ The Dublin Philosophical Society was one of the many groups which enabled this: it was established in 1683 by William Molyneux, lawyer and very famous disciple of John Locke, to whom he posed the great thought experiment on perception that was to become known as 'Molyneux's Problem.8 Another was the Belfast Society, formed in 1705 by Irish Presbyterian ministers, James Kirkpatrick and John Abernathy 
of Antrim. It challenged 'Old Light' covenanting theology with more liberal 'New Light' Presbyterianism (the aforementioned Dr Victor Ferguson was a member). ${ }^{9}$ Also important was 'the Molesworth Circle' of Glasgow graduates in Dublin, a group which included the philosopher Francis Hutcheson and James Arbuckle, the poet and critic who established the Dublin Weekly Journal from 1725. ${ }^{10}$ Amy Prendergast and Michael Brown attest that a cross-confessional associational culture of this kind was made all the stronger for the extremely confessional nature of Ireland's officially recognised (and state-sponsored) civic public sphere, and fuelled by booming print industries in Dublin, Cork and Belfast. ${ }^{11}$ These recent works clearly vindicate Brown's claim that Ireland 'was not trapped by the sectarian politics of the seventeenth century and was not in a moribund catatonic state in the eighteenth century. Rather it was a vigorous and controversial participant in the transcontinental experiment of creating a modern world, defined by the reimaging of the universe based on the premise that man, not God, was the starting point of understanding.' ${ }^{2}$

As James Kelly and Toby Barnard have also made clear, Irish physicians were an important part of this increasingly civic and scholarly culture. ${ }^{13}$ Many sought professional advancement through membership of such clubs, through high positions and offices, or through forms of elite enterprise, like book collecting. The Dublin physician Edward Worth, for example, created a private library of almost 4,400 books, many with exceptionally rare bindings. When he died in 1733, he left this collection to Dr Steevens's Hospital in his capacity as a governor. ${ }^{14}$ But Worth was clearly exceptional: many practising physicians did not have physical access to such resources or groups - they were dispersed across Ireland and simply could not afford to accumulate that kind of cultural capital, particularly during the tumultuous seventeenth century. This is why Victor Ferguson requested in a letter addressed via the Fellows of the College of Physicians that Sloane 'throw in a letter now and then into the office and aquaint me what books of note come forth ... What I already have are the marrow of all antient and modern authors till about 1688 . I have none since. ${ }^{15}$ However, as this chapter seeks to show, this lack of physical access to scholarly resources and communities did not prevent Irish physicians from being valued members of a wider associational culture of international epistolary exchange. They were not refused entry to such networks on account of their lack of usefulness, as Rawdon and Ferguson's comments might imply: on the contrary, the medical and natural historical material that 
they collected and exchanged was highly valued by renowned physicians and scholarly collectors, such as Sloane. As shall be demonstrated, this is partly because of the general ways in which medical communities functioned in Britain and Ireland in the seventeenth and eighteenth centuries. But it was also partly because the collection and circulation of natural knowledge took on a new epistemological value during this period.

\section{Circulating information in medical communities}

The intellectual and practical limitations facing physicians across Britain and Ireland between 1680 and 1750 influenced the ways that they interacted with one another. Conceptual instability, professional factionalism, relative institutional weakness and commercial vagaries all combined to create a culture in which physicians were continually required to circulate news, observations and objects. The flood of new ideas and natural objects from the New World had significantly disrupted established social and intellectual hierarchies in medical practice and theory, and new commercial opportunities were being increasingly exploited. ${ }^{16}$ As early as 1626 , Charles I had written to the lord deputy, Henry Cary, 1st Viscount Falkland, to suggest that a chartered body like the Royal College of Physicians in London might be able to tackle the 'wandering, ignorant mountebanks and empirics, who for want of restraint do much abound to the daily impairing of our healths, \& hazarding of our lives in general of our good subject there [in Ireland]. ${ }^{17}$ But, as Harold Cook has shown, by the end of the seventeenth century the king's optimistic belief in the strength of the Royal College of Physicians of London had been proven false: its attempts to preserve the authority of academic physic by withholding medical information and publicly prosecuting unlicensed practitioners had backfired spectacularly, severely weakening its overall authority within the medical marketplace. ${ }^{18}$ They simply could not control the amount of medical information being exchanged, either for cash or credit. The 'Fraternity' or College of Physicians established in Dublin in 1667 was equally unable to combat the huge range of healers relied upon by the public. In both countries, a broad range of practitioners were able to practice due to the general lack of access to 'official' or educated medical healers, the continuing popularity of folk remedies and the increasing commercialisation of medical remedies and practices. 
The fact that Early Modern medical institutions struggled so much to regulate practice and theory was of little consequence to the patients themselves. Illness was a communal experience in the Early Modern period: long before a practitioner of any kind was called, patients would discuss their symptoms, circumstances and treatments with family, friends and neighbours around them, exploring and evaluating their bodies by calibrating their experiences according to the knowledge or testimonials of others. ${ }^{19}$ The bishop of Clonfert, Mordecai Carey, for example, reported to his family physician, the English scientist and physician James Jurin, that his wife now 'wears a Plaister on the left breast, a Plaister that is recommended by some Neighbouring Ladies who have been in her case. ${ }^{20}$ Many of these accounts of tried-and-tested remedies from the community, often using local herbs or other plants, were captured and stored within manuscript medical recipe books. Elaine Leong recently argued that we should approach such collections as both repositories and archives, created in various collaborations across spatial, geographical and temporal boundaries, and adjusted according to testing and experience. ${ }^{21}$

In initiating their correspondence with a physician, patients would employ this accumulated experience, combining the knowledge gained from diverse discussions with their surrounding friends and family with any learning or opinion they might have themselves regarding their condition, and any wider knowledge which they were able to obtain, adding any contextual details they believed, for whatever reason, could be relevant or useful in diagnosis. ${ }^{22}$ Over the course of Carey and Jurin's correspondence between June 1733 and February 1735 , for example, Carey related Catherine's pain both as described by her and interpreted by him, observed a swelling in her breast, noted limited movement, offered information on possible treatments as well as local discussions of them, and detailed her menstrual cycle and general wellbeing. In a letter dated 9 June 1733, Cary employed a number of sensory descriptions to describe the state of her urine, observing that it now appeared 'like the grounds of a small yeasty beer' and 'leaves a white sediment on the side of a large glass from top to bottom: which sediment to the eye looks white and greasy, but to the fingers feels gritty \& indeed when rubbed along the glass you hear the sound of sand.'23 This range of information was included in order to try to overcome the distance between embodied and evaluative understandings of illness. In the attempt to diagnose via correspondence, all physicians had to engage with this muddle of information and 
attempt to create useful meaning from it by comparing many overlapping strands of experience or opinion, be they recipe, ancient herbal or newly published pamphlet.

This continuous circulation, comparison and evaluation of information was also reflected in the more explicit regulation of practice that went on between physicians. As Patrick Wallis has shown, the vagaries of the commercial marketplace demanded that practitioners collaboratively evaluate the worth of their material products, techniques and sources of information as 'the fragmentation and diffusion of production, limitations of assaying techniques and the legitimacy of substitutions and variation in some recipes meant that fraud was widely suspected. ${ }^{24}$ Physicians exchanged notes on their own practice as well as that of others in order to ensure best practice and to protect themselves from potentially ruinous public censure. In 1698, Victor Ferguson again got in touch with Sloane regarding the health of one Mr James Hamilton of Bangor, Sloane's cousin by marriage. ${ }^{25}$ Ferguson had recently treated Hamilton and was alerting Sloane to an altercation that had arisen between him and an attending apothecary, $\mathrm{Mr}$ Fairly, whom Ferguson described as 'a man of idleness and pleasure'. According to Ferguson, Fairly had given Hamilton a concoction which had made him worse, and then blamed it on him as the physician. In his defence, Ferguson described both Hamilton's symptoms (which he believed was measles but may have been smallpox) and treatment: an infusion of rhubarb, manna and whey, and a surgeon who unfortunately 'missed his aim, however sufficient vent was made for the discharge'. $\mathrm{He}$ also cited the three local practitioners who could be called on to support his claims of correct treatment: Mr Probey and Mr Cumming, both of Dublin, and one Dr Johnston. ${ }^{26}$ By collecting all the information he could surrounding the case - even down to witnesses that could be consulted as evidence - and then presenting it to Sloane through a letter, Ferguson was ensuring both that his professional reputation and personal relationship with Sloane remained intact, regardless of whether Hamilton lived to tell the tale.

With the wealth of unknown or unlicensed persons practising, individual skill and trustworthiness had to be verified through correspondence. In 1734, for example, a Manchester physician called John Barlow got in touch with Sloane to ask him his opinion of one 'silver toung'd Maynard', a man of Irish extraction frequently seen in the local coffeehouses in 'character of a Physician, who has left Court for retirement': 
At my first acquaintance, I was mightily taken with his happy way of Elocution, \& invited him to settle in our town, which he declining, fixt at Wigan; where, upon my recommendation to a leading Gentleman in that neighbourhood, Mr Dickinson of Wrightington, he was soon introduced to Mr Bradshaw, \& most of the families thereabouts, \& got into a very promising business; but being sadly afraid of any body enquiring, what, or where he came from, which is very unusual on such occasions, made people more inquisitive of his character; whence arose many discoveries. ${ }^{27}$

New physicians, like all external visitors to Early Modern communities, were required to present their credentials and have their claims verified. ${ }^{28}$ Otherwise, prospective patients made their own enquiries: one 'discovery' this community made was that Maynard had previously set up as a solicitor in Sheffield, something which was claimed by a 'travelling Druggist'. Subsequently run out of Wigan by the Rector (whose son was a physician and so, understandably, did not take kindly to imposters), Maynard then made out that he had gone to London before coming back to Manchester apparently on the orders of Sloane, 'the College, and all the great ones of the profession'. Whether or not Maynard was a fraud is unclear, but it seems not, as some months later he himself wrote to Sloane, saying: 'As I am convinced I can not otherwise discharge my obligations to you but by shewing my deep sense of them.' He enclosed a set of stones coughed up by a patient with consumption in the hopes that it would be a gift fit for Sloane's collection of rarities. ${ }^{29}$ This implies that, despite all suspicions and appearances to the contrary, Maynard's reputation and ability to practice had been saved through his confirmation within various correspondence networks and, particularly, Sloane's endorsement. This affair reveals a number of things. Firstly, that medical knowledge and authority was understood to be limited across geographical distances and social reach. Secondly, that even though many individuals partook in the regulatory circulation of information, this knowledge could only be verified by physicians further up the ladder. Successful medical professionals had more access to contacts and resources, and were therefore regularly called on by the medical community to supply such gaps in knowledge. Finally, it shows that, in return for such circulation and arbitration, participants could receive many possible rewards, ranging from the increased ability of knowing whom to trust, to the addition of items of materia medica or natural history to their collections. 
At all points in medical practice, then, physicians were required to collect and collate information from wildly differing sources, and compare it to the collected knowledge of those who they understood to have a wider access to information. This was an accepted part of successful medical practice: those with more resources were expected to share them. Victor Ferguson himself stated as much in one of his earliest letters to Sloane, addressed via the College of Physicians, where he asked Sloane to send him medical books, leaving 'that and all others to your candid judgement. As you esteem them and they are in vogue amongst the most learned. I have not time to read, yea I hate quacks and collectors, I find many of the germans in that strain, and would have nothing but what is new and of value tending to physick directly or indirectly. ${ }^{30}$ In February 1697, he wrote again, lamenting his intellectual isolation:

The correspondent I formerly fixed on being now removed, And none of note going from hence lately has necessitated to be almost an Ignoramus of what passes amongst you this year by past except only what I hear by second hand from Dublin. Your own native goodness then with other items has emboldened me to beg the favour of a short account of what has been lately published amongst you worth reading ... [A] ny rational practick book may be published or Any natural history may Improve the practick part of Physick; for I would not Spend time in reading, any Empirick or froathy tractate notional books whose hypotheses is grounded in an airy train; nor any that are purely theory. My main drift is to Improve in ordine ad praxim [in order to practice]. ${ }^{31}$

The best and quickest way for physicians all across Britain and Ireland to become more informed about their practice, whether this was regarding the latest books or advice on which practitioners to trust with a particular procedure, was by contacting successful and wellconnected physicians and asking them. In return, consulting physicians accumulated more contacts, resources, social credit and other byproducts of enquiry such as items of materia medica (as with Maynard's stones) or natural history: all could be useful in the further circulation of valuable information. This is why, when Ferguson wrote to Sloane again in 1698, asking to be informed of whether, among other things, any satisfactory trials had been made into the curing of dysentery with the Ipecacuanha root, he offered such exchange: 'And if you desire 
any information of any herb, stone or mineral are in this part of the Kingdome I shall do my utmost to answer your desire, for I take liberty to acquaint you I think I know all that has yet been discovered here.. ${ }^{32}$

The value of such an offer for Sloane is not to be underestimated. In terms of his profession, Sloane would gain more knowledge to help him in the treatment of patients and the regulation of practice. But it would also facilitate a wider goal, which was the consolidation and systematisation of natural knowledge in its very broadest sense. Sloane's understanding of the ways in which such unreliable information was processed and corroborated within communities of natural knowledge, and the potential value of seemingly unlikely information, was established through his experiences as a physician. As Sloane himself stated in a letter to John Locke (a medically trained philosopher who was also 'in the habit of jotting down ... information passed on to him by other doctors ${ }^{33}$ ), no scrap of information was easily dismissed until it was proven to be useless:

I have ventur'd to send those Small books to Mr Churchill to be sent you that you pick out any thing you fancy and distribute the rest for making plumm pyes, I confesse I love to look over such traces because most of them are used to such like purposes that deserve sometimes better usage for which reason I have turn'd over many thousands within this 10 . years and have bound up many volumms, which you know you will doe me a favour at any time to command what may be for Your purpose. ${ }^{34}$

In an earlier conversation, Locke had urged Sloane to publish the case he had discovered regarding a woman with a giant spleen, in the hopes that it would 'give great light' about humours in the abdomen and help the recognition of polyps as a disease in their own right: 'If there were collections enough of their hystory \& symptoms to build any theory on \& lay a foundation for their cure. ${ }^{35}$ Physicians were to redefine themselves in this period as the 'natural historians' of disease, collecting diverse accounts of cases and their treatments in order to build up systems of knowledge. ${ }^{36}$

\section{Collecting and testing common observations}

All kinds of material were therefore deemed valuable by physicians and naturalists of this period. Indeed, the esteemed Restoration natural 
philosopher Robert Boyle had argued for the collection of the broadest range of objects and remedies two decades earlier: 'Nor should we only expect some improvements to the therapeutic part of physic from the writings of so ingenious [a] people as the Chinese, but probably the knowledge of physicians might not be inconsiderable increased, if men were a little more curious about the observations and experiments, suggested partly by the practice of midwives, barbers, old women, empirics, and the rest of that illiterate crew, that presume to meddle with physic among ourselves. ${ }^{37}$ Many practitioners put this thinking into practice, and gathered all the remedies and specimens they could find to test. The Irish surgeon and anatomist (and co-founder of the Dublin Philosophical Society), Allen Mullen, wrote to Robert Boyle in 1685/86 concerning Boyle's Of the Reconcileablness of Specifick Medicines (London, 1685) which, he said

besides giving me some profitable hints, brought several things into my mind agreeable to what you have there deliver ... What you mention out of Hippocrates of elaterium I have known more than once true of an infusion of senna and manna in water and taken by nurses when the children they suckles were designed to be purged. It is a common observation in this country to have butter stink of garlic when the cattle feed either on crows' garlic or ramsons. ${ }^{38}$

In this letter, Mullen also discussed the statement of individuals personally connected with him (in this case the niece of an archbishop and her daughter) regarding 'Coventry blue' thread for the relief of cramp, and a terrible bleeding from the mouth which had been cured by poultices made from stamped-on nettles. A month later, the bishop of Derry and tutor of Jonathan Swift, St George Ashe, wrote to John Bainbrigg: 'Doctor Mullen tried lately an experiment upon the famous Irish herb called Mackenboy or Tithymalus Hybernicus, which is by the natives reported to be so strong a purge that even the carrying it about one in their clothes is sufficient to produce the effect. This fabulous story, which has long prevailed, he proved false by carrying its root for 3 days in his pocket without any alteration of that sort. ${ }^{39}$

Here we can see how individual physicians were concerned with relating new learning back to folk remedies and vice versa. Whether the folk remedies were disproved outright (as with the Irish herb) or were curiously connected to some other kind of new finding, all results of such experimentation would encourage further enquiry and circulation. 
Making comparisons like this could also allow physicians to justify older treatments in an innovative manner - by tracing antecedents back through medical theory and practice, practitioners were able to neutralise and assimilate potentially damaging new knowledge, and make it work for them and their patients. ${ }^{40}$ Physicians built their authority on being able to locate, connect and compare diverse strands of medical knowledge, and interrogate information in order to make it conducive to future use. Their authority depended in a large part on the breadth of their connections and the diversity of their resources. Irish physicians were, therefore, highly valuable to physicians and naturalists such as Sloane: they were able to offer materials from the communities and lands around them, crucial for the kinds of medical and natural historical systematisation many physicians and naturalists were involved in.

Another example of this kind of activity is when Reverend John Ray, naturalist of Essex and Sloane's friend and mentor, sent him a number of observations that he had received from physicians in Ireland regarding hemlock. The first two observations were sent to Ray from Dr Nathaniel Wood of Kilkenny, who related that: 'A certain woman eating by mistake some Roots (as he supposes) of common Hemlock, among Parsnips, was immediately seized with Raving and Madness, talk'd obscenely, and could not forebear Dancing, on which exercise she would have given her Cow for a Bagpipe.' Ray, himself, was not convinced and cited a number of printed histories to disprove this source, and recounted that their mutual friend James Petiver claimed to have eaten some pieces of hemlock root in company and been fine. Ray also noted: 'The common People generally believe that the Roots which cause these Symptoms, are no other than old Parsneps, which have continued for some Years in the Ground, and therefore call them Madneps.' The other was an observation about a horse which Ray said: 'I shall give you in his own Words without making any Reflections upon it.' Both were printed in the Philosophical Transactions of $1695 .^{41}$ Then, a couple of years later, Ray wrote again with an account of the 'direfull effects' of Hemlock-Water-Dropwort, which had been sent to him by 'Dr Francis Vaughun a learned Physitian in Ireland, living at Chonmell in the County of Tipperary.42 Vaughun had seen some recent dispute between Ray and another writer, Dr Johnson, on the venomous quality of the plant in question and so sent a story which he had had from his brother-in-law, who had experienced it. Eight young lads had gone fishing in the county but, after eating 'a great deale' of roots, five convulsed and died before the next morning, and of the 
other three 'one run stark mad, but come to his right reason again the next morning. Another had his hair \& nails fall off. The third [Vaughun's brother in law] alone escaped without receiving any harm'. Vaughun could not say whether this was down to his constitution, or his eating less of the root, but believed his brother-in-law had been saved because he had run away when he saw the first man fall and, because it was two miles or so, stopped to drink some milk warm from the cow on the way. Vaughun said that he believed his violent sweating 'did doubly expell and carry off the venemous particles' and that the draught of warm milk 'did acts its part by involving the acid or acrimonious poison particles \& rendring them inactive ... But this is but my conjecture, wch I willingly submit to more mature judgements'.

Though the incident had happened thirty years before, its communication was prompted by Vaughun seeing Ray's opinion in print, and this also encouraged him to include an account that he knew of a Dutchman who had died through similar circumstances. In his letter to Sloane, Ray then discussed the existence of 'severall parallel \& no less tragical Histories [ ${ }^{\circ}$ of later date] of the ... destruction of divers persons by the eating of the root' and related where he had found them recorded, writing 'Wherefore I think it is for the interest of mankind that all persons be sufficiently cautioned against venturing to eat of this $\&[\wedge$ indeed $]$ any other unknown herb or root, lest they incurr the same fate, and in order thereto that such Histories be made publick \& transmitted to posterity as what I send you may be by being inserted into the Philosophical Transactions. This was something Sloane, as Secretary of the Royal Society, could easily do, and it was published there in $1698 .{ }^{43}$

\section{Scholarly alliances}

Printing this material served a number of purposes: it widened the reach of potential connections for the information contained therein while simultaneously rewarding all those who participated in the circulation of information and boosting the image of the Royal Society by increasing the breadth of its connections. Increasing the circulation of information across Britain, Ireland and the world in this way encouraged and facilitated all kinds of wider research, something which contemporaries were aware of. ${ }^{44}$ The physician Thomas Molyneux, for example, wrote in 1697 ostensibly to thank Sloane for reading a letter he had written about some recently uncovered large horns in front of the Society: 
But Sir I should take it very kindly, if you would freely impart to me your own, or any other of the Fellows of the Royall Society's thoughts concerning the several Particulars I have there proposed: and Especially, whether the Large Horned Deer of Ireland was certainly the same with the Moose of America this I Phancy may be easily made out by you in London, with the greatest Certainty; where I doubt not, but you may Procure some Genuine MooseHornes brought from the West Indies, with one or other of the Collectors of Natural Rarietys in the Citty and by Comparing them with the Description and figure I have given of the Hornes found here in Ireland, the Matter may be Determin'd beyond all Doubt or Contest. $^{45}$

This, Molyneux said, would give him 'further Encouragement to Spend what Leasure Hours I Can Command from the attendance on my Troublesome profession in Prosecuting Enquireys about the History of Nature, which I finde is a part of Learning you have very successfully laboured in'. In 1701, too, Molyneux explicitly stated that, as his medical and physical insights appeared to be valued by the Royal Society, he would be sure to send them whenever he could. ${ }^{46}$

The communication of all kinds of unknown, unusual or even false material was highly valued in overlapping medical and natural historical networks, because it enabled propositions to be tested, systems to be built and practice to be improved. Such exchange used and expanded the correspondence networks that physicians across Britain and Ireland employed in the normal course of their professional duties. Aiding such expansion helped to broaden the range of sources physicians could use to their advantage, thereby improving their evaluative and interpretive abilities, their ability to navigate a dangerous marketplace and their appearance of authority within such correspondence networks. This is why Sloane and other collectors like him rewarded all those who participated in and furthered the circulation of medical and natural historical information by giving them information, books, objects from his collection, the latest Philosophical Transactions or, even better, the opportunity of being published in the Philosophical Transactions. It also appears to be the reason why he sought to strengthen the scholarly alliances between England and Ireland (and, indeed, Scotland): in 1695, the Secretary to the Dublin Philosophical Society, Owen Lloyd, wrote thanking Sloane on behalf of the Society for the 'valuable present' of his own Duplicates, saying: 'We will omitt noe opportunity of making 
you sensible how much We esteem them, and wish We had anything worth your acceptance but hope that time may enable Us to make You Some returne in such naturall Raritys, as may be collected by the joint endeavours of so many of Us, as labour in these Discoverys, and assure Yourselfe that when nothing else can keep us together the Memory of this Favour, with what We have receiv'd from the Illustrious Society will be able to do it. ${ }^{37}$ Doing so ensured the broadest coverage of the British Isles and, therefore, the best medical and natural knowledge. Contemporaries recognised the benefits of increasing the dissemination of medical and natural historical knowledge: by the 1750 s, collecting and communicating natural knowledge of all kinds was seen to be both fashionable and useful. It facilitated the growth of both journal publications and increasing sociable scholarly activities, such as the founding of the Dublin Society in 1731, with its experimental farm, art school and botanical garden, as well as the Physico-Historical Society in 1744, in which apothecaries, doctors, lawyers, churchmen and gentlemen came together to discuss all kinds of topics, from agriculture, soil and climate, to mathematics and navigation, to art and antiquities.

\section{Conclusion}

Despite how intellectually isolated many Irish individuals (particularly those outside of Dublin) may have felt in the late seventeenth century, many actively participated in the growing culture of scholarly exchange through correspondence, allowing them to overcome many physical and material limitations. Repeating his frequent request for accounts of the latest books of medicine, Ferguson wrote to Sloane: 'You may conjecture the disadvantage of this country practice that thereby we consume much time in riding and spending too much time in conference abstract from our trade when in houses of note; this obliges me to be cautious what I read for I can't read all. ${ }^{38}$ But the help that Irish physicians required to get up-to-date information was really just the same as the help physicians in Manchester required to verify unknown practitioners. Their requests were rewarded with the further circulation of medical information through letters, publication or the exchange of natural historical or medical specimens, and this created further obligations and opportunities for exchange. Physicians like Sloane encouraged this, because it helped them build their social and professional authority. This shows how closely intertwined the quest for successful medical practice was with the quest for natural specimens. Sloane and physicians like him regularly 
used their medical expertise and reputations as well-known and trusted practitioners to cultivate possible contacts for the supply of botanical and other natural historical objects or pieces of information which, in turn, they were regularly called on to circulate to through their medical networks. This meant that, even though scholars and practitioners in Ireland felt they were at a disadvantage, they could participate (and, indeed, be highly valued) in circles of scholarly exchange - particularly wider cultures of medical collecting and testing - often simply by providing information about local healing practices or recipes, or communicating items of natural history. This allowed them to participate in wider scholarly cultures of exchange and interaction, connecting them up to a broad range of other international networks, institutions and individuals and, in doing so, transcending geographical, political, temporal and confessional boundaries.

\section{Notes}

1 BL, Sloane MS 4036, Arthur Rawdon to Hans Sloane, Moira, 10 May 1688, fo. 35 .

2 Ibid., Rawdon to Sloane, Moira, 24 June 1691, fo. 105.

3 Ibid., Victor Ferguson to Sloane, Belfast, 14 July 1691, fo. 106.

4 Anne Goldgar, Impolite Learning: Conduct and Community in the Republic of Letters, 1680-1750 (New Haven, CT, 1995).

5 M. Purcell, "Settled in the north of Ireland" or, where did Sloane come from?', in A. Walker, A. MacGregor and M. Hunter (eds), From Books to Bezoars: Sir Hans Sloane and His Collections (London, 2012), pp. 24-32.

6 J. Livesey, Civil Society and Empire: Ireland and Scotland in the EighteenthCentury Atlantic World (New Haven, CT, 2009); I. McBride, 'The edge of Enlightenment: Ireland and Scotland in the eighteenth century', Modern Intellectual History, 10 (2013), pp. 135-51.

7 I. McBride, Eighteenth-Century Ireland: The Isle of Slaves (Dublin, 2009).

8 D. Park, 'Locke and Berkeley on the Molyneux Problem', Journal of the History of Ideas, 30 (1969), pp. 253-60; P. Kelly, 'William Molyneux and the spirit of liberty in eighteenth-century Ireland', Eighteenth-Century Ireland: Iris An Dá Chultur (hereafter ECI), 3 (1988), pp. 133-48; J. Livesey, 'The Dublin Society in eighteenth-century Irish political thought', The Historical Journal, 47 (2004), pp. 615-40.

9 I. McBride, Scripture Politics: Ulster Presbyterianism and Irish Radicalism in the Late Eighteenth Century (Oxford, 1998), pp. 41-62; P. Griffin, 'Defining the limits of Britishness: the "New" British History and the meaning of the Revolution settlement in Ireland for Ulster's Presbyterians', Journal of British Studies, 39 (2000), pp. 263-87. 
10 M. A. Stewart, 'John Smith and the Molesworth Circle', ECI, 2 (1987), pp. 89-102; J. A. I. Champion, 'Enlightened erudition and the politics of reading in John Toland's Circle', The Historical Journal, 49 (2006), pp. $111-41$.

11 J. Kelly and M. J. Powell (eds), Clubs and Societies in Eighteenth-Century Ireland (Dublin, 2010); A. Prendergast, Literary Salons Across Britain and Ireland in the Long Eighteenth Century (London, 2015); M. Brown, The Irish Enlightenment (Cambridge, MA, 2016); T. Barnard, Brought to Book: Print in Ireland, 1689-1784 (Dublin, 2017).

12 Brown, The Irish Enlightenment, p. 7.

13 J. Kelly, 'The emergence of scientific and institutional medical practice in Ireland, 1650-1800', in G. Jones and E. Malcolm (eds), Medicine, Disease and the State in Ireland, 1650-1940 (Cork, 1999), pp. 21-39; T. Barnard, 'Wider cultures of eighteenth-century Irish doctors', in J. Kelly and F. Clark (eds), Ireland and Medicine in the Seventeenth and Eighteenth Centuries (Farnham, 2010), pp. 183-95.

14 There they remain, protected by the terms of the original trust, still in the room and cases originally designed for them. See: W. J. Cormack, 'Some commercial and other sources for the Edward Worth Library (1733)', in G. O'Brien and F. O'Kane (eds), Georgian Dublin (Dublin, 2008), pp. 165-74; D. Westerhof (ed.), The Alchemy of Medicine and Print: The Edward Worth Library, Dublin (Dublin, 2010). See also chapter 8 by Boran in this volume.

15 BL, Sloane MS 4036, Ferguson to Sloane, Belfast, 14 July 1691, fo. 106.

16 H. J. Cook, 'Physicians and natural history', in N. Jardine, J. A. Secord and E. C. Spary (eds), Cultures of Natural History (Cambridge, 1996), pp. 91-105; Roy Porter, Quacks: Fakers and Charlatans in Medicine (Stroud, 2000); H. J. Cook, Matters of Exchange: Commerce, Medicine and Science in the Dutch Golden Age (New Haven, CT, 2007); M. Jenner and P. Wallis (eds), Medicine and the Market in England and Its Colonies, c.1450-1850 (Basingstoke, 2007).

17 J. D. H. Widdess, A History of the Royal College of Physicians of Ireland, 1654-1963 (Edinburgh, 1963), p. 4.

18 H. J. Cook, The Decline of the Old Medical Regime in Stuart London (Ithaca, NY, 1986); H. J. Cook, 'The Rose case reconsidered: physicians, apothecaries, and the law in Augustan England', Journal of the History of Medicine and Allied Sciences (JHMAS), 45 (1990), pp. 527-55.

19 L. McCray Beier, Sufferers and Healers: The Experience of Illness in Seventeenth-Century England (London, 1987); D. Porter and R. Porter, Patient's Progress: Doctors and Doctoring in Eighteenth-Century England (Oxford, 1989); M. Louis-Courvoisier and S. Pilloud, 'The intimate experience of the body in the eighteenth century: between interiority and exteriority', Medical History, 47 (2003), p. 452; A. Withey, 
Physick and the Family: Health, Medicine and Care in Wales, 1600-1750 (Manchester, 2011).

20 Quoted in W. Wild, Medicine-By-Post: The Changing Voice of Illness in Eighteenth-Century British Consultation Letters and Literature (Amsterdam, 2006), p. 87.

21 E. Leong, 'Collecting knowledge for the family: recipes, gender and practical knowledge in the early modern English household', Centaurus, 55 (2013), pp. 81-103.

22 L. Wynne Smith, "An account of unaccountable distemper": the experience of pain in early eighteenth-century England and France', EighteenthCentury Studies, 41 (2008), pp. 459-80; Wild, Medicine-By-Post, p. 462.

23 Wild, Medicine-By-Post, p. 84.

24 P. Wallis, 'Competition and cooperation in the early modern medical economy', in Wallis and Jenner (eds), Medicine and the Market, p. 60.

25 Hamilton had been in touch with him a few months earlier to thank him belatedly for the gift of scientific books Sloane had sent him while Hamilton was in Jamaica: 'I designed by the first to return you my thanks for them, but the leaveing the Kingdome at such time as the Small Pox was among my children, I was put by all Rules of Civilitie.' BL, Sloane MS 4037, James Hamilton to Sloane, Bangor, 30 January 1698, fo. 21.

26 Ibid., Ferguson to Sloane, Belfast, 14 May 1698, fo. 73.

27 BL, Sloane MS 4053, John Barlow to Sloane, Manchester, 22 Aug. 1734, fo. 257.

28 C. Muldrew, The Economy of Obligation: The Culture of Credit and Social Relations in Early Modern England (Basingstoke, 1998); A. Shepard and P. Withington (eds), Communities in Early Modern England: Networks, Place, Rhetoric (Manchester, 2000); A. Shepard, Accounting for Oneself: Worth, Status, and the Social Order in Early Modern England (Oxford, 2015).

29 BL, Sloane MS 4053, William Maynard to Sloane, Wigan, 17 Oct. 1734, fo. 289.

30 BL, Sloane MS 4036, Ferguson to Sloane, Belfast, 14 July 1691, fo. 106. $\mathrm{He}$ also requested a 'one of the best microscopes for herbs, for one $\mathrm{Mr}$ Shered of Oxford St' - presumably the botanist William Sherard who was, at that point, working for Arthur Rawdon at Moira, and adding several species from the Ulster countryside to Irish flora - and also the 'truest and latest, and fullest' of maps of the Alps, Savoy and Piedmont, Hungary, and Ireland. See also ibid., Ferguson to Sloane, Dublin, 14 Jan. 1693, fo. 139.

31 BL, Sloane MS 4037, Ferguson to Sloane, Belfast, 4 Feb. 1697, fo. 25.

32 Ibid., Victor Ferguson to Sloane, Belfast, 14 May 1698, fo. 73.

33 K. Dewhurst, 'Some letters of Dr Charles Goodall (1642-1712) to Locke, Sloane, and Sir Thomas Millington', JHMAS, 17 (1962), p. 489.

34 Sloane to John Locke, 11 Dec. 1696, in The Correspondence of John Locke, ed. E. S. de Beer (8 vols, Oxford, 1979), v, p. 737. 
35 BL, Sloane 4036, Locke to Sloane, 14 September 1694, fo. 185.

36 H. J. Cook, 'Physick and natural history', in P. Barker and R. Ariew (eds), Revolution and Continuity: Essays in the History and Philosophy of Early Modern Science (Washington, DC, 1991), p. 73. See also W. D. Churchill, 'Bodily differences? Gender, race and class in Hans Sloane's Jamaican medical practice, 1687-1688', JHMAS, 60 (2005), pp. 391-44; H. J. Cook, 'Markets and cultures: medical specifics and the reconfiguration of the body in early modern Europe', Transactions of the Royal Historical Society, 21 (2011), pp. 123-45.

37 Quoted in Cook, Decline of the Old Medical Regime, p. 166.

38 Allen Mullen to Robert Boyle, Dublin, 26 Feb. 1685/6, in Papers of the Dublin Philosophical Society 1683-1709, ed. K. T. Hoppen (2 vols, Dublin, 2008), ii, no. 23. Consulted during a fellowship at the Edward Worth Library in Dublin, with thanks to Elizabethanne Boran. Mullen refers to an unnamed 'primate. This was either Francis Marsh, archbishop of Dublin or Michael Boyle, archbishop of Armagh.

39 St George Ashe to John Bainbrigg, Dublin, 26 Mar. 1687, in ibid., no. 357. This letter was read at the Royal Society in London on 13 July 1687.

40 A. M. Roos, 'Luminaries in medicine: Richard Mead, James Gibbs, and solar and lunar effects on the human body in early modern England', BHoM, 74 (2000), pp. 433-57.

41 Philosophical Transactions of the Royal Society (London, 1695), pp. 634-6.

42 BL, Sloane MS 4037, John Ray to Sloane, Black Notley, 16 Mar. 1697, fos $40-1$.

43 Philosophical Transactions of the Royal Society (London, 1698), pp. 84-6.

44 E. Yale, Sociable Knowledge: Natural History and the Nation in Early Modern Britain (Philadelphia, PA, 2016).

45 BL, Sloane MS 4036, Thomas Molyneux to Sloane, Dublin, 22 May 1697, fo. 314 .

46 BL, Sloane MS 4038, Molyneux to Sloane, Dublin, 22 Feb. 1701, fo. 140.

47 BL, Sloane MS 4036, Owen Lloyd to Sloane, Dublin, 7 May 1695, fo. 209.

48 BL, Sloane MS 4037, Ferguson to Sloane, Belfast, 14 May 1698, fo. 73. 